\title{
Inhibitors of Protein Tyrosine Phosphatase PTP1B With Anticancer Potential
}

\author{
TOMASZ KOSTRZEWA ${ }^{1}$, JOANNA STYSZKO ${ }^{1}$, MAGDALENA GORSKA-PONIKOWSKA ${ }^{1}$, \\ TOMASZ SLEDZINSKI ${ }^{2}$ and ALICJA KUBAN-JANKOWSKA ${ }^{1}$ \\ ${ }^{1}$ Department of Medical Chemistry, Medical University of Gdansk, Gdansk, Poland; \\ ${ }^{2}$ Department of Pharmaceutical Biochemistry, Medical University of Gdansk, Gdansk, Poland
}

\begin{abstract}
Background/Aim: PTP1B tyrosine phosphatase is involved in the development of many types of cancers, such as breast cancer or lung cancer. Therefore, PTPIB is a promising target for anticancer therapy. The purpose of this review was to present the studies on selected PTPIB inhibitors as a possible treatment and describe the latest trends of current research in this field. Materials and Methods: This literature review was performed using the PubMed database and the analysis of previous research studies of our Department. Results: Recent studies have shown that PTP1B, due to its implication in oncogenic transformation, represents a promising drug target. Conclusion: The selected compounds that are effective PTP1B inhibitors can be considered a promising anticancer treatment, both as monotherapy and in combination with other anticancer drugs.
\end{abstract}

Reversible phosphorylation of proteins is an intracellular signal transduction mechanism, regulating processes such as proliferation, differentiation, growth and apoptosis (1). Phosphorylation and dephosphorylation of proteins affect their functions, including the catalytic activity of enzymes. Protein phosphorylation depends on the activity of protein kinases and phosphatases. Protein kinases attach a phosphate group from ATP to serine, threonine or a tyrosine residue, whereas phosphatases hydrolytically remove this group (2). Disruptions to this mechanism may lead to many diseases, including congenital defects (3), neoplasms, autoimmune or metabolic disorders $(4,5)$.

Correspondence to: Alicja Kuban-Jankowska, Department of Medical Chemistry, Medical University of Gdansk, Debinki 1 Street, 80210 Gdansk, Poland. Tel: +48 583491450, Fax: +48 583491456,e-mail: alicja.kuban-jankowska@gumed.edu.pl

Key Words: PTP1B phosphatase, anticancer compounds, tyrosine phosphatase's inhibitors, review.
There are 107 different phosphatase genes in the human genome, of which 81 encode for catalytically active enzymes. Depending on the primary structure of the catalytic domain, there are four classes of protein tyrosine phosphatases. Class I is the largest category and contains tyrosine-specific and dualspecific phosphatases. Class II includes one tyrosine-specific LMPTP protein. Class III is represented by three tyrosinethreonine phosphatases involved in the control of the cell cycle. In contrast to class I-III phosphatases, which have a catalytically active cysteine residue in the active center, four tyrosine phosphatases from class IV or serine-tyrosine phosphatases have aspartic acid residues in their center (6). There are two groups of class I PTPs: receptor-like phosphatases (RPTPs) and soluble in cytoplasm, non-receptor enzymes (NRPTPs). RPTPs contain an extracellular sequence, a transmembrane sequence and a cytoplasmic sequence that includes two domains: proximal, catalytic (D1) and distal, regulatory (D2) (7). NRPTPs consist of a conservative domain responsible for dephosphorylation and a domain that modulates the activity and intracellular transport of the enzyme (8). PTP1B is a nonreceptor type 1 phosphatase. Abnormal regulation of PTP1B has been observed in breast cancer, lung cancer, multiple myeloma and Noonan syndrome. PTP1B has also been reported to be overexpressed in type II diabetes and obesity. Therefore, PTP1B is a promising target in the pharmacotherapy of the aforementioned conditions $(9,10)$. In this article we reviewed scientific reports on tyrosine phosphatase's potential inhibitors.

\section{PTP1B Activates Oncogenic Src Kinases}

PTP1B contributes to oncogenic properties through activation of non-receptor tyrosine kinase Src, which is deregulated in multiple tumor types (11). The crucial role of Src kinases in tumor development is due to their effect on proliferation, survival, adhesion, migration, invasion and metastasis. Src kinase activity has been reported to be elevated in many human cancer cell lines, e.g. breast cancer, lung cancer and 
ACTIVE

INACTIVE

INACTIVE

INACTIVE

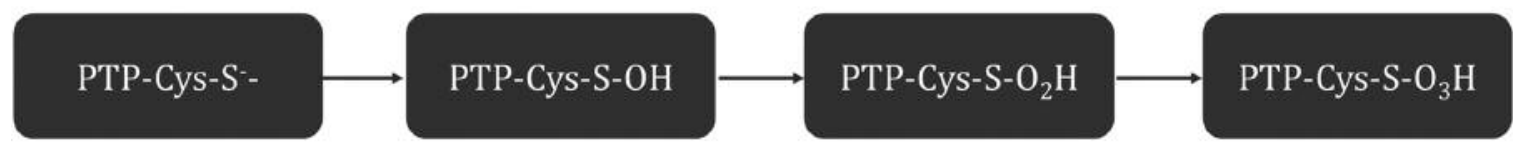

Figure 1. Regulation of PTPs activity by oxidation of catalytic cysteine.
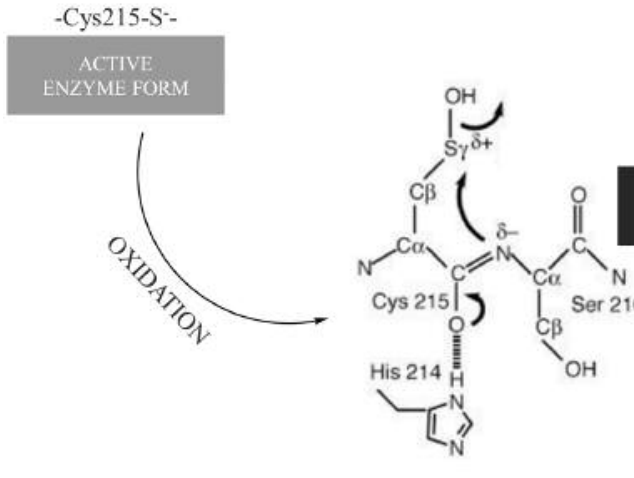

Sulfenic acid
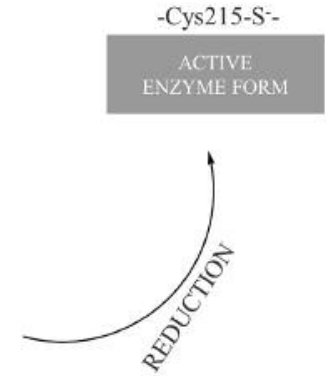

Sulfenylamide

Figure 2. Reversibility of oxidation by formation of sulfenylamide.

colon cancer cells (12-15). However, Src inhibitors have shown only minimal therapeutic activity in various types of solid tumors, when used as a single agent in recent early-phase clinical trials (11). Src kinase activity can be regulated in several ways. Two major phosphorylation sites are present on human Src: the autophosphorylation site Y419 and the negative regulatory $\mathrm{COOH}$-terminal phosphorylation site Y530 (16). Several protein tyrosine phosphatases are capable of activating Src by dephosphorylating Y530. These include PTP- $\alpha$, PTP- $\varepsilon$, SHP-1, SHP-2, and PTP1B (17).

Many studies have shown that PTP1B can act as an activator of Src kinase, increase tumorigenicity and promote tumor progression of colon cancer cells (18) and pancreatic cancer (19).

\section{PTP1B Phosphatase as a Drug Target}

Research is focused on the mechanisms of regulation of PTPs' activity due to its involvement in the development of many diseases. For example, PTPs are important for the proper functioning of the immune system, and alterations in the expression of the encoding genes have been associated with the development of various cancers, such as multiple myeloma, lymphoma or glioma (20). Due to the fact that PTPs exert a key role in tumor biology, they may be promising targets for the development of new anticancer diagnostic and therapeutic strategies $(1,21)$. Contrasting research results have indicated that PTP1B can play both a pro-oncogenic and a tumorsuppressing role (22). PTPs have also been associated with the development of some autoimmune diseases, including severe combined immunodeficiency (SCID) or multiple sclerosis (MS) $(23,24)$ and with the development of Noonan syndrome characterized by malformations (25). PTPs are also linked with the pathogenesis of metabolic disorders and viral infections (26). PTP1B tyrosine phosphatase is also a regulator of leptin and insulin signaling pathways. It has been shown that inhibition of PTP1B enhances the activity of insulin and leptin. Consequently, PTP1B has become a new attractive therapeutic target in the treatment of both type 2 diabetes and obesity (27).

Since PTPs play a key role in the numerous signaling pathways involved in the pathogenesis of many diseases. There is an increasing interest for the development and synthesis of new strong, efficient and selective PTPs inhibitors. The main difficulty regarding this project is the high homology between the catalytic domains shared by all PTPs (28). Potential inhibitory compounds should bind to both the catalytic center and the secondary binding site and induce allosteric inhibition $(29,30)$.

\section{Mechanisms of Inactivation of PTPs}

The catalytic residue in the enzymatic center of PTPs is in the form of a thiolate anion, and the sensitivity to oxidation is due to low $\mathrm{pKa}(\sim 5.4)$. The oxidation of catalytic cysteine leads to inhibition of the enzyme's dephosphorylation ability, including the transfer of the phosphate group from the substrate to the catalytic cysteine. Depending on the degree of oxidation, the remaining cysteine residues in the active site may be converted to sulphenic acid $(\mathrm{SOH})$, sulfinic acid $\left(\mathrm{SO}_{2} \mathrm{H}\right)$ or sulphonic acid $\left(\mathrm{SO}_{3} \mathrm{H}\right)(31)$ (Figure 1). 


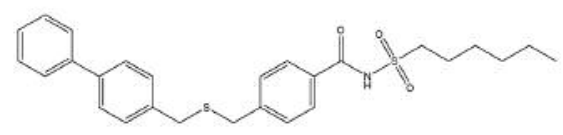

KY-226 (4)

$I C_{50}=0.28 \mu \mathrm{m}$

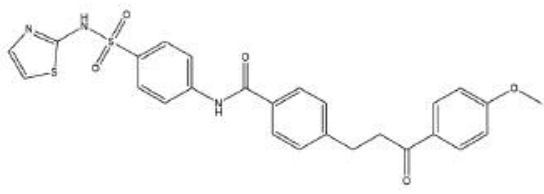

Compound 16 (36)

$I C_{50}=3.20 \mu \mathrm{m}$

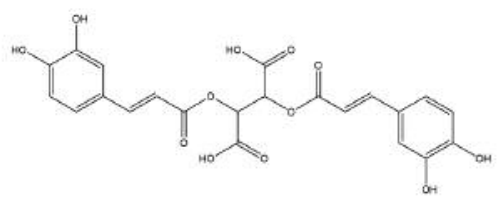

Cichoric Acid (37)

$\mathrm{IC}_{50}=10.51 \mu \mathrm{m}$

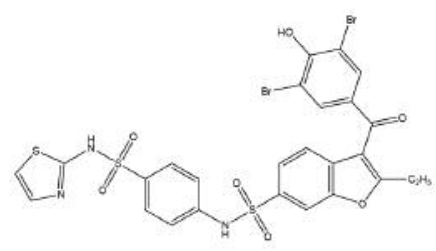

Compound 3 (35)

$\mathrm{IC}_{50}=8.00 \mu \mathrm{m}$

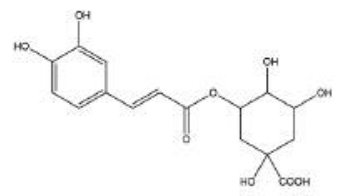

Chlorogenic acid (37)

${ }^{\prime} C_{50}=9.82 \mu \mathrm{m}$

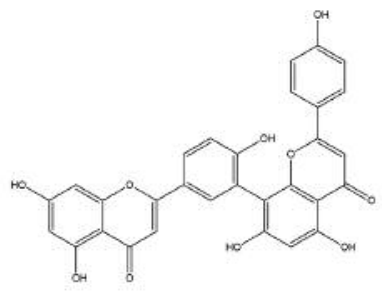

Amentoflavone (38)

$\mathrm{IC}_{50}=7.30 \mu \mathrm{m}$

Figure 3. Selected allosteric PTP1B inhibitors.

Inactivation of PTPs by oxidation of the catalytic cysteine residue to sulfenic acid and their activation by reduction of this form to the thiolate anion is a characteristic mechanism of regulation of protein tyrosine phosphatases. The inactive oxidized form may return to the active reduced form by converting the sulfenic acid to the intermediate sulfenylamide. The close proximity of cysteine and histidine residues within the catalytic center of the protein causes polarization of the amide bond, allowing the nucleophilic attack of the nitrogen atom in the serine residue on the sulfur atom of the oxidized form of the cysteine residue. This leads to condensation and the formation of a covalent bond between the sulfur and nitrogen atoms. The sulfenylamide can then be reduced to the active thiolate anion (Figure 2). Oxidation of the cysteine residue to sulfinic and sulfonic acid is an irreversible process. For this reason, the emerging sulfenylamide induces conformational changes in the catalytic center of the enzyme, protecting the cysteine residue against irreversible inactivation, and also facilitating the activation of the enzyme by reducing agents such as thioredoxin or glutathione (32).

\section{Promising Inhibitors of Protein Tyrosine Phosphatase PTP1B}

Considering the fact that the regulatory mechanism of tyrosine phosphatases involves mainly the oxidation of catalytic cysteine, the potential inhibitors of PTPs should possess oxidizing properties or induce generation of oxidative compounds. Recent studies have shown that hydrogen peroxide decreases the activity of PTP1B, and more powerful oxidants, such as peracids, have an even much stronger effect (33). However, oxidizing compounds have low specificity, as they are effective against all PTPs.

Discovery of the active site directed inhibitors of PTP1B is very challenging due to the highly conserved sequence of the active center. There are also multiple charge requirements of the ligands, which will lead to loss of selectivity and permeability. Identification of the PTP1B allosteric site (34) has revealed a new field for discovering potent and selective ligands for therapeutic intervention which are presented on Figure 3 (4, 35-38).

PTP1B can be inactivated by mimicking the natural PTPs substrate, phosphotyrosine. Phosphotyrosine in the mimetic 


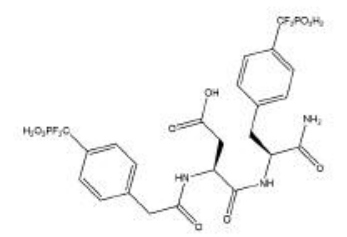

Compound 40 (44)

$K_{i}=2.40 \mathrm{nM}$

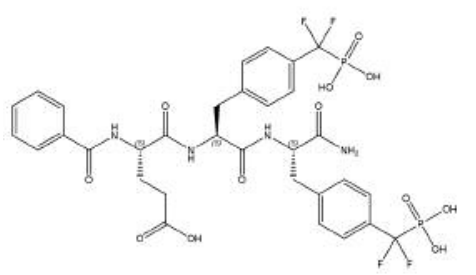

BzN-EJJ-amide(1) (45)

$I C_{50}=5.00 \mathrm{nM}$

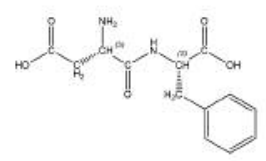

Asp-Phe (46)

$I_{50}=52.60 \mu \mathrm{m}$

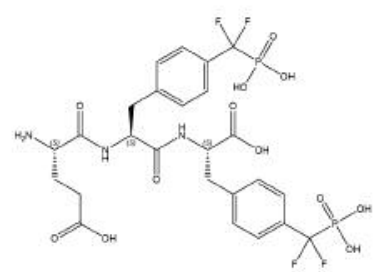

EJJ-amide (45)

$I_{50}=40.00 \mathrm{nM}$

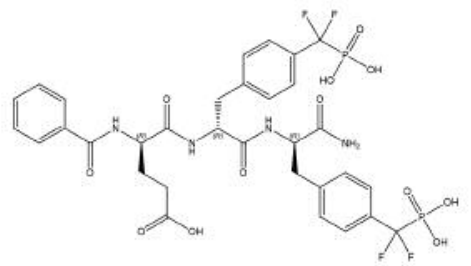

BzN-EJJ-amide(2) (45)

$I_{50}=1.00 \mu \mathrm{m}$

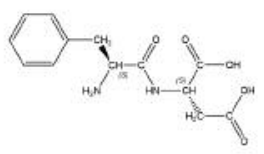

Phe-Asp (46)

${ } \mathrm{C}_{50}=\mathbf{5 2 . 1 0 \mu \mathrm { m }}$

Figure 4. Selected peptide PTP1B inhibitors.<smiles>O=C(O)CCCC[C@H]1CCSS1</smiles>

\section{Alpha-lipoic acid (ALA) (5)}<smiles>O=CC=Cc1ccccc1</smiles>

Cinnamaldehyde (52)<smiles>COc1cc(/C=C/C(=O)CC(=O)/C=C/c2ccc(O)c(O)c2)ccc1O</smiles>

Curcumin (52)

Figure 5. Selected natural compounds that decrease the activity of PTP1B.

structures was replaced by sulfothyrosine, thiophosphotyrosine or phosphonomethylphenylalanine (39). Many recent studies have demonstrated that therapeutic peptides represent a promising strategy for the treatment of cancer $(40,41)$. The peptides are rapidly synthesized, easily modified, and less toxic and immunogenic than e.g. recombinant antibodies $(42,43)$ (Figure 4). As shown in Figure 4, even a slight change in the structure of the inhibitory compound may lead to a lower inhibitory effect (44-46). Such correlation was obsevered related to aurintricarboxylic acid (ATA) which reveals high inhibitory effect on PTP1B (47). However, the experiments conducted on other tyrosine phosphatase YopH has shown that the analogs of ATA are weaker inhibitors than their precursor (48).

There are also many natural compounds that inhibit various types of enzymes, including PTPs. Some of these PTP inhibitors can be extracted from plants, algae or microorganisms (49).
Recent studies have shown that selected natural dietetic ingredients can be considered as potential anticancer agents (50, 51). Moreover, some of these compounds presented on Figure 5 are able to reduce the activity of PTPs $(5,52)$.

\section{Conclusion}

In conclusion, PTPs regulate the levels of protein tyrosine phosphorylation under normal and pathological conditions and have both positive and negative effects on cellular signal transduction. Abnormal activity of these enzymes is associated with numerous disorders, including carcinogenesis. Reactive oxygen species (ROS), which are involved in the development and progression of cancer, regulate due to reversible oxidation PTPs activity. Protein tyrosine phosphatases may be potential targets for anticancer therapy, because of their key role in the 
formation and development of tumors. PTP1B phosphatase is a particularly important target in the treatment of cancer.

\section{Conflicts of Interest}

None of the Authors have any conflicts of interest to disclose regarding this study.

\section{Authors' Contributions}

All Authors participated in the manuscript writing and reviewing. The Figures were prepared by TK.

\section{Acknowledgements}

The Authors acknowledge the financial support from the project IP2015 038774 from Polish Ministry of Science and Higher Education. TS acknowledges to project 2016/22/E/NZ4/00665 from Polish National Science Centre.

\section{References}

1 Zhang S and Zhang Z: PTP1B as a drug target: recent developments in PTP1B inhibitor discovery. Drug Discov Today 12: 373-381, 2007. PMID: 17467573. DOI: 10.1016/ j.drudis.2007.03.011

2 Johnson LN and Lewis RJ: Structural basis for control by phosphorylation. Chem Rev 101: 2209-2242, 2001. PMID: 11749371. DOI: $10.1021 / \mathrm{cr} 000225 \mathrm{~s}$

3 Tartaglia M, Mehler EL, Goldberg R, Zampino G, Brunner HG, Kremer H, van der Burgt I, Crosby AH, Ion A, Jeffery S, Kalidas $\mathrm{K}$, Patton MA, Kucherlapati RS and Gelb BD: Mutations in PTPN11, encoding the protein tyrosine phosphatase SHP-2, cause Noonan syndrome. Nat Genet 29: 465-468, 2001. PMID: 11704759. DOI: $10.1038 / \mathrm{ng} 772$

4 Ito Y, Fukui M, Kanda M, Morishita K, Shoji Y, Kitao T, Hinoi $\mathrm{E}$ and Shirahase H: Therapeutic effects of the allosteric protein tyrosine phosphatase 1B inhibitor KY-226 on experimental diabetes and obesity via enhancements in insulin and leptin signaling in mice. J Pharmacol Sci 137: 38-46, 2018. PMID: 29731242. DOI: 10.1016/j.jphs.2018.03.001

5 Kuban-Jankowska A, Gorska-Ponikowska M and Wozniak M: Lipoic acid decreases the viability of breast cancer cells and activity of PTP1B and SHP2. Anticancer Res 37: 2893-2898, 2017. PMID: 28551626. DOI: 10.21873/anticanres.11642

6 Alonso A, Sasin J, Bottini N, Friedberg I, Friedberg I, Osterman A, Godzik A, Hunter T, Dixon J and Mustelin T: Protein tyrosine phosphatases in the human genome. Cell 117: 699-711, 2004. PMID: 15186772. DOI: 10.1016/j.cell.2004.05.018

7 Den Hertog J, Groen A and Van Der Wijk T: Redox regulation of protein-tyrosine phosphatases. Arch Biochem Biophys 434: 11-15, 2005. PMID: 15629103. DOI: 10.1016/j.abb.2004.05.024

8 Takakura K, Beckman JS, MacMillan-Crow LA and Crow JP: Rapid and irreversible inactivation of protein tyrosine phosphatases PTP1B, CD45, and LAR by peroxynitrite. Arch Biochem Biophys 369: 197-207, 1999. PMID: 10486138. DOI: 10.1006/abbi.1999.1374

9 Zhang Z-Y and Lee S-Y: PTP1B inhibitors as potential therapeutics in the treatment of Type 2 diabetes and obesity. Expert Opin Investig Drugs 12: 223-233, 2003. PMID: 12556216. DOI: $10.1517 / 13543784.12 .2 .223$
10 Verma M, Gupta SJ, Chaudhary A and Garg VK: Protein tyrosine phosphatase $1 \mathrm{~B}$ inhibitors as antidiabetic agents - A brief review. Bioorg Chem 70: 267-283, 2017. PMID: 28043717. DOI: $10.1016 /$ j.bioorg.2016.12.004

11 Zhang S and Yu D: Targeting Src family kinases in anti-cancer therapies: Turning promise into triumph. Trends Pharmacol Sci 33: 122-128, 2012. PMID: 22153719. DOI: 10.1016/ j.tips.2011.11.002

12 Parsons SJ and Parsons JT: Src family kinases, key regulators of signal transduction. Oncogene 23: 7906-7909, 2004. PMID: 15489908. DOI: $10.1038 /$ sj.onc. 1208160

13 Summy $J$ and Gallick G: Src family kinases in tumor progression and metastasis. Cancer metastasis Rev 22: 337-358, 2003. PMID: 12884910 . DOI: $10.1023 / \mathrm{A}: 1023772912750$

14 Biscardi JS, Ishizawar RC, Silva CM and Parsons SJ: Tyrosine kinase signalling in breast cancer: Epidermal growth factor receptor and c-Src interactions in breast cancer. Breast Cancer Res 2: 203, 2000. PMID: 11250711. DOI: 10.1186/bcr55

15 Lai YH, Chen MH, Lin SY, Lin SY, Wong YH, Yu SL, Chen HW, Yang $\mathrm{CH}$, Chang GC and Chen JJW: Rhodomycin A, a novel Srctargeted compound, can suppress lung cancer cell progression via modulating Src-related pathways. Oncotarget 6: 26252-26265, 2015. PMID: 26312766. DOI: $10.18632 /$ oncotarget.4761

16 Bjorge J, Jakymiw A and Fujita D: Selected glimpses into the activation and function of Src kinase. Oncogene 19: 5620-5635, 2000. PMID: 11114743. DOI: 10.1038/sj.onc.1203923

17 Zheng X, Resnick R and Shalloway D: Mitotic activation of protein-tyrosine phosphatase $\alpha$ and regulation of its Srcmediated transforming activity by its sites of protein kinase C phosphorylation. J Biol Chem 277: 21922-21929, 2002. PMID: 11923305. DOI: 10.1074/jbc.M201394200

18 Zhu S, Bjorge J and Fujita D: PTP1B contributes to the oncogenic properties of colon cancer cells through Src activation. Cancer Res 67: 10129-10137, 2007. PMID: 17974954. DOI: 10.1158/0008-5472.CAN-06-4338

19 Paladino D, Yue P, Furuya H, Acoba J and Rosser C: A novel nuclear Src and p300 signaling axis controls migratory and invasive behavior in pancreatic cancer. Oncotarget 7: 7253-7267, 2016. PMID: 26695438. DOI: 10.18632/oncotarget.6635

20 Navis AC, Van Den Eijnden M, Schepens JTG, Hooft Van Huijsduijnen R, Wesseling P and Hendriks WJAJ: Protein tyrosine phosphatases in glioma biology. Acta Neuropathol 119: 157-175, 2010. PMID: 19936768. DOI: 10.1007/s00401-009-0614-0

21 Zhang ZY: Protein tyrosine phosphatases: Prospects for therapeutics. Curr Opin Chem Biol 5: 416-423, 2001. PMID: 11470605.

22 Lessard L, Stuible M and Tremblay ML: The two faces of PTP1B in cancer. Biochim Biophys Acta - Proteins Proteomics 1804: 613-619, 2010. PMID: 19782770. DOI: 10.1016/ j.bbapap.2009.09.018

23 Kung C, Pingel J, Heikinheimo M and Klemola T: Mutations in the tyrosine phosphatase CD45 gene in a child with severe combined immunodeficiency disease. Nature 6: 343-345, 2000. PMID: 10700239. DOI: 10.1038/73208

24 Tchilian E, Wallace D and Wells R: A deletion in the gene encoding the CD45 antigen in a patient with SCID. J Immunol 166: 1308-1313, 2001. PMID: 11145714. DOI: 10.4049/ jimmunol.166.2.1308

25 Kuban-Jankowska A, Górska M, Knap N, Cappello F and Woźniak M: Protein tyrosine phosphatases in pathological process. Front Biosci 20: 377-388, 2015. PMID: 25553456. DOI: $10.2741 / 4314$ 
26 Zhang ZY: Protein-tyrosine phosphatases: biological function, structural characteristics, and mechanism of catalysis. Crit Rev Biochem Mol Biol 33: 1-52, 1998. PMID: 9543627. DOI: 10.1080/10409239891204161

27 Cho H: Protein Tyrosine Phosphatase 1B (PTP1B) and Obesity. Vitam Horm 91: 405-424, 2013. PMID: 23374726. DOI: 10.1016/B978-0-12-407766-9.00017-1

28 Bialy L and Waldmann H: Inhibitors of protein tyrosine phosphatases: Next-generation drugs? Angew Chemie Int 44: 3814 3839, 2005. PMID: 15900534. DOI: 10.1002/anie. 200461517

29 Barr AJ, Ugochukwu E, Lee WH, King ONF, Filippakopoulos P, Alfano I, Savitsky P, Burgess-Brown NA, Müller S and Knapp $\mathrm{S}$ : Large-scale structural analysis of the classical human protein tyrosine phosphatome. Cell 136: 352-363, 2009. PMID 19167335. DOI: $10.1016 /$ j.cell.2008.11.038

30 Barr AJ: Protein tyrosine phosphatases as drug targets: Strategies and challenges of inhibitor development. Future Med Chem 2 1563-1576, 2010. PMID: 21426149. DOI: 10.4155/fmc.10.241

31 Chiarugi P and Cirri P: Redox regulation of protein tyrosine phosphatases during receptor tyrosine kinase signal transduction. Trends Biochem Sci 28: 509-514, 2003. PMID: 13678963. DOI: 10.1016/S0968-0004(03)00174-9

32 Salmeen A, Andersen JN, Myers MP, Meng TC, Hinks JA, Tonks NK and Barford D: Redox regulation of protein tyrosine phosphatase 1B involves a sulphenyl-amide intermediate. Nature 423: 769-773, 2003. PMID: 12802338. DOI: 10.1038/nature 01680

33 Kuban-Jankowska A, Gorska M, Tuszynski JA, Churchill CD, Winter P, Klobukowski $M$ and Wozniak $M$ : Inactivation of protein tyrosine phosphatases by peracids correlates with the hydrocarbon chain length. Cell Physiol Biochem 36: 1069-1083, 2015. PMID: 26112900. DOI: $10.1159 / 000430280$

34 Shinde RN, Siva Kumar G, Eqbal S and Sobhia ME: Screening and identification of potential PTP1B allosteric inhibitors using in silico and in vitro approaches. PLoS One 13, 2018. PMID: 29912965. DOI: 10.1371/journal.pone.0199020

35 Wiesmann C, Barr KJ, Kung J, Zhu J, Erlanson DA, Shen W, Fahr BJ, Zhong M, Taylor L, Randal M, McDowell RS and Hansen SK: Allosteric inhibition of protein tyrosine phosphatase 1B. Nat Struct Mol Biol 11: 730-737, 2004. PMID: 15258570. DOI: $10.1038 / \mathrm{nsmb} 803$

36 Tang YB, Lu D, Chen Z, Hu C, Yang Y, Tian JY, Ye F, Wu L, Zhang $\mathrm{ZY}$ and Xiao Z: Design, synthesis and insulin-sensitising effects of novel PTP1B inhibitors. Bioorg Med Chem Lett 23: 2313-2318, 2013. PMID: 23499238. DOI: 10.1016/j.bmcl. 2013.02.073

37 Baskaran SK, Goswami N, Selvaraj S, Muthusamy VS and Lakshmi BS: Molecular dynamics approach to probe the allosteric inhibition of PTP1B by chlorogenic and cichoric acid. J Chem Inf Model 52: 2004-2012, 2012. PMID: 22747429. DOI: $10.1021 / \mathrm{ci} 200581 \mathrm{~g}$

38 Lee J-Y, Jung K-W, Woo E-R and Kim Y: Docking study of biflavonoids into PTP1B. Bull Korean Chem. Soc 29: 1479-1483 2008. DOI: $10.5012 /$ bkcs.2008.29.8.1479

39 Jenkins KE, Higson AP, Seeberger PH and Caruthers MH: Solidphase synthesis and biochemical studies of O -Boranophosphopeptides and O -Dithiophosphopeptides. J Am Chem Soc 124: 6584-6593, 2002. PMID: 12047178. DOI: 10.1021/ja0126576

40 Cicero AFG, Fogacci F and Colletti A: Potential role of bioactive peptides in prevention and treatment of chronic diseases: a narrative review. Br J Pharmacol 174: 1378-1394, 2017. PMID: 27572703. DOI: 10.1111/bph.13608
41 Blanco-Míguez A, Gutiérrez-Jácome A, Pérez-Pérez M, PérezRodríguez G, Catalán-García S, Fdez-Riverola F, Lourenço A and Sánchez B: From amino acid sequence to bioactivity: The biomedical potential of antitumor peptides. Protein Sci 25: 10841095, 2016. PMID: 27010507. DOI: 10.1002/pro.2927

42 Boohaker RJ, Lee MW, Vishnubhotla P, Perez JM and Khaled AR: The use of therapeutic peptides to target and to kill cancer cells. Curr Med Chem 19: 3794-3804, 2012. PMID: 22725698.

43 McGregor DP: Discovering and improving novel peptide therapeutics. Curr Opin Pharmacol 8: 616-619, 2008. PMID: 18602024. DOI: $10.1016 /$ j.coph.2008.06.002

44 Shen K, Keng YF, Wu L, Guo XL, Lawrence DS and Zhang ZY: Acquisition of a specific and potent PTP1B inhibitor from a novel combinatorial library and screening procedure. J Biol Chem 276: 47311-47319, 2001. PMID: 11584002. DOI: 10.1074/jbc.M106568200

45 Asante-Appiah E, Patel S, Dufresne C, Roy P, Wang Q, Patel V, Friesen RW, Ramachandran C, Becker JW, Leblanc Y, Kennedy BP and Scapin G: The structure of PTP-1B in complex with a peptide inhibitor reveals an alternative binding mode for bisphosphonates. Biochemistry 41: 9043-9051, 2002. PMID: 12119018. DOI: $10.1021 /$ bi0259554

46 Kostrzewa T, Sahu KK, Gorska-Ponikowska M, Tuszynski JA and Kuban-Jankowska A: Synthesis of small peptide compounds, molecular docking, and inhibitory activity evaluation against phosphatases PTP1B and SHP2. Drug Des Devel Ther 12, 2018. PMID: 30584278. DOI: 10.2147/ DDDT.S186614

47 Kuban-Jankowska A, Sahu KK, Gorska-Ponikowska M, Tuszynski JA and Wozniak M: Inhibitory activity of iron chelators ATA and DFO on MCF-7 breast cancer cells and phosphatases PTP1B and SHP2. Anticancer Res 37: 4799-4806, 2017. PMID: 28870898. DOI: 10.21873/anticanres.11886

48 Kuban-Jankowska A, Sahu KK, Gorska M, Niedzialkowski P, Tuszynski JA, Ossowski T and Wozniak M: Aurintricarboxylic acid structure modifications lead to reduction of inhibitory properties against virulence factor YopH and higher cytotoxicity. World J Microbiol Biotechnol 32: 163, 2016. PMID: 27562597. DOI: $10.1007 / \mathrm{s} 11274-016-2123-3$

49 Kakeya H, Imoto M, Takanashi Y, Naganawa H, Takeuchi T and Umezawa K: Dephostatin, a novel protein tyrosine phosphatase inhibitor produced by Streptomyces. II. Structure determination. J Antibiot (Tokyo) 46: 1716-1719, 1993. PMID: 8270494. DOI: 10.7164/antibiotics.46.1716

50 Park J and Jang HJ: Anti-diabetic effects of natural products an overview of therapeutic strategies. Mol Cell Toxicol 13: 1-20, 2017. PMID: 29395440. DOI: 10.1016/j.phrs.2018.01.015

51 Nobili S, Lippi D, Witort E, Donnini M, Bausi L, Mini E and Capaccioli S: Natural compounds for cancer treatment and prevention. Pharmacol Res 59: 365-378, 2009. PMID: 19429468. DOI: 10.1016/j.phrs.2009.01.017

52 Kostrzewa T, Przychodzen P, Gorska-Ponikowska M and KubanJankowska A: Curcumin and Cinnamaldehyde as PTP1B Inhibitors With Antidiabetic and Anticancer Potential. Anticancer Res 39: 745749, 2019. PMID: 30711953. DOI: 10.21873/ anticanres.13171

Received March 29, 2019 Revised April 29, 2019 Accepted May 3, 2019 